\title{
The reliability of adductor tubercle as an anatomical landmark for joint line restoration in revision knee arthroplasty: a systematic review
}

\author{
Berardo Di Matteo $^{1,2}$, Daniele Altomare ${ }^{1,2} \wedge$, Andrea Dorotei ${ }^{1,2}$, Giovanni Francesco Raspugli ${ }^{1,2}$, Tommaso \\ Bonanzinga $^{1,2}$, Maurilio Marcacci ${ }^{1,2}$, Elizaveta Kon ${ }^{2,3}$, Francesco Iacono ${ }^{1,2}$ \\ ${ }^{1}$ Department of Biomedical Sciences, Humanitas University, Via Levi Montalcini 4, 20090 Pieve Emanuele, Milan, Italy; ${ }^{2}$ Humanitas Clinical and \\ Research Center, IRCCS, Via Manzoni 56, 20089 Rozzano, Milan, Italy; ${ }^{3}$ First Moscow State Medical University, Sechenov University, Bol'shaya \\ Pirogovskaya Ulitsa, 19c1, 119146 Moscow, Russia \\ Contributions: (I) Conception and design: F Iacono, B Di Matteo; (II) Administrative support: M Marcacci, T Bonanzinga, GF Raspugli, E Kon; (III) \\ Provision of study materials or patients: D Altomare, A Dorotei, E Kon; (IV) Collection and assembly of data: D Altomare, A Dorotei; (V) Data \\ analysis and interpretation: B Di Matteo, F Iacono, D Altomare, A Dorotei, GF Raspugli, T Bonanzinga; (VI) Manuscript writing: All authors; (VII) \\ Final approval of manuscript: All authors. \\ Correspondence to: Daniele Altomare. Humanitas Clinical and Research Institute, Via A. Manzoni 113, 20089 Rozzano, Milan, Italy. \\ Email: dott.danielealtomare@gmail.com.
}

\begin{abstract}
Joint line (JL) restoration is one of the major challenges in revision total knee arthroplasty (rTKA). There is debate regarding the most reliable methodology for the assessment of JL level during revision surgery. Among the strategies, the use of adductor tubercle (AT) as an anatomical landmark has been proposed. The purpose of this paper is to systematically review the available literature to understand the reliability of AT ratio to identify the JL, and the advantages and drawbacks of its application. A research was performed on the PubMed, Embase, Cochrane and Google Scholar databases based on the following inclusion criteria for articles' selection: (I) clinical reports of any level of evidence, (II) written in the English language, (III) published from 2010 to 2020, (IV) dealing with the use of the adductor tubercle as a landmark to restore JL in revision TKA. All relevant data were extracted by two independent investigators, and discrepancies were resolved by discussion and consensus. A total of 13 studies were included: nine were radiographic evaluations, 3 clinical reports and 1 was an ex-vivo study. Radiographic studies highlighted that AT is a landmark easy to identify, with high intra and inter-observer agreement, irrespective of gender, age and size of the patient. The comparison with other bony landmarks revealed superior reliability in favor of AT. Also during surgical procedures, AT can be safely located and some clinical studies confirmed that AT ratio helps surgeon in re-establishing a correct JL and achieve ligament balancing even in complex revision cases. AT is a reliable and easily detectable landmark, and AT ratio is a valid tool to determine the JL level and help surgeons to restore the JL and simultaneously achieve knee ligament balancing in r-TKA.
\end{abstract}

Keywords: Adductor tubercle (AT); ratio; joint line (JL); revision total knee arthroplasty (rTKA)

Submitted May 02, 2020. Accepted for publication Sep 30, 2020.

doi: 10.21037/atm-20-3681

View this article at: http://dx.doi.org/10.21037/atm-20-3681

^ ORCID: 0000-0002-7063-5816. 


\section{Introduction}

Revision of total knee arthroplasty (rTKA) is one of the toughest procedures in knee surgery. Standing the huge increasing of indications for primary TKA all over the world, rTKA will consistently increase its incidence in the next decade, to nearly duplicate by 2030 (1). Therefore, most of orthopedic surgeons will have to face the challenge of rTKA daily. In fact, revision procedures remain a surgical challenge for several technical reasons, and among the key requirements to achieve a good outcome, the restoration of physiological joint line (JL) is of utmost relevance because it allows ligament balance and normal knee kinematics to be restored (2). The JL height restoration has been considered a milestone in rTKA among experienced surgeons (3-5). In fact, abnormal JL elevation has been defined in several papers as the reason for poor clinical outcomes, mainly due to anterior knee pain and limited range of motion as a consequence of resultant patella baja (6-8). Although complete restoration of native JL height is often very hard, due to the concurrent presence of bone deficiency and joint deformity after primary TKA, there is still some debate regarding the most appropriate method for the assessment of the femoro-tibial JL position. In recent years, it has been hypothesized that the Adductor Tubercle (AT), which represents the insertion of the vertical fibers of the adductor magnus tendon, could be reliably used as a pre-op and intra-op landmark to correctly restore JL height. Its use has been firstly proposed in 2013 (9), based on the findings that AT could be identified in standard plan radiographs but also easily during surgery, thus representing a reliable landmark for surgeons. Furthermore, AT is close enough to the JL to allow comfortable measurements and it is not influenced by bony deformities which are commonly found in the context of knee OA.

The rationale of using the adductor tubercle as a reliable landmark to assess JL in rTKA has then been described by a number of authors, especially considering the correlation with the trans-epicondylar femoral width (FW, i.e., the distance between the most prominent points of the medial and lateral epicondyles), leading to the introduction of the concept of AT ratio, i.e., the (AT-JL distance)/FW (9-16). However, some specific critical issues were raised applying this method to different ethnicities (i.e., Caucasian versus Asiatic) and to different clinical situation (i.e., severe OA deformity, bone deficiency, osteophytes, JL narrowing). The aim of this paper is to perform a qualitative systematic review of the state of art about the use of the adductor tubercle in rTKA, in order to: (I) understand the reliability of AT ratio in the assessment of JL height both at imaging and during revision surgery; (II) identify advantages and drawbacks associated to the use of this anatomical landmark.

We present the following systematic review in accordance with the PRISMA reporting checklist (available at http:// dx.doi.org/10.21037/atm-20-3681).

\section{Methods}

\section{Literature search}

A literature search was carried out on the PubMed, Embase, Cochrane and Google Scholar databases on $30^{\text {th }}$ August, 2020, using the following keywords that were combined together in different search to achieve maximum search strategy sensitivity: [("arthroplasty, replacement, knee" OR ("arthroplasty" AND "replacement" AND "knee") OR "knee replacement arthroplasty" OR ("total" AND "knee" AND "arthroplasty") OR "total knee arthroplasty") AND revision AND adductor AND ("Tubercle" OR "tuberculum")].

\section{Inclusion/exclusion criteria}

All the retrieved articles were screened by title and abstract, using the following inclusion criteria for article selection: (I) clinical reports of any level of evidence, (II) written in the English language, (III) published from 2010 to 2020, (IV) dealing with the use of the adductor tubercle as a landmark to restore joint line in knee replacement surgery. After the initial screening, we excluded all duplicate articles, articles from non-peer reviewed journals or articles lacking access to the full text. Conference presentations, narrative reviews, editorials and expert opinions were also excluded. A PRISMA flowchart of the selection and screening method is provided in Figure 1.

\section{Data extraction and analytic approach}

Two investigators extracted relevant data independently and performed a qualitative analysis of results. Discrepancies between the two reviewers were resolved by discussion and consensus, and the final results were reviewed by the senior investigators. All the data retrieved from the analysis of the studies included in the present review have been summarized in Table 1.

\section{Main outcomes}

The main outcomes of the present qualitative review were: 


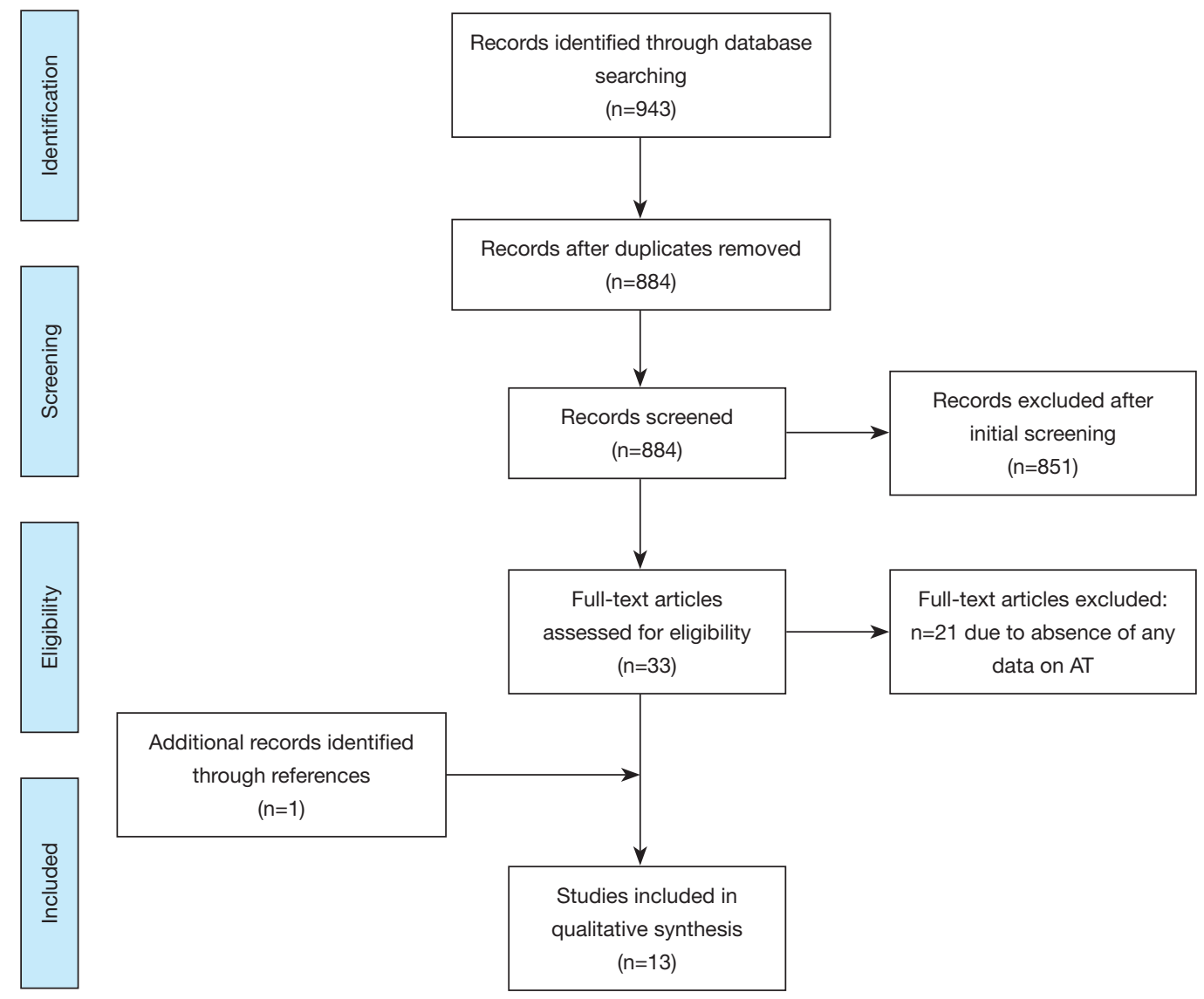

Figure 1 PRISMA Flowchart resuming the papers' selection process.

(I) to identify radiographic methods involving the use of AT to calculate JL height; (II) to identify studies where intra-op. application of AT was documented, in order to understand the reliability of this anatomical landmark and its potential advantages and drawbacks.

\section{Risk of bias assessment}

In the present review, both radiographic, cadaveric and intra-operative studies were included. After analyzing the design and the data of the trials, risk of bias assessment could not be performed using a standardized tool or checklist. Therefore, the authors, by discussion and consensus, identified a series of relevant items that could be applied to the specific studies considered, in order to detect their potential bias: (I) presence of power analysis to calculate sample size (i.e., number of $\mathrm{X}$-rays or patients evaluated); (II) number of observers involved in radiographic and/or intra-op measurements; (III) independence of each observer during measurements; (IV) professional profile of the observers (orthopaedic surgeons or radiologists or both); (V) presence of data concerning intra- and inter-observers reliability; (VI) eventual repetition of measurements at different times.

All these data were retrieved by two investigators and any discrepancy was resolved by discussion and consensus, with a final review by the senior investigators. A comprehensive summary has been provided in Table 2 .

\section{Statistical analysis}

Given the heterogeneity of the data collected, it was not possible to pool them and perform a meta-analysis. Therefore, no statistical tests have been used. A descriptive analysis and qualitative synthesis of data were provided in the present systematic review.

\section{Ethics}

Given the nature of the present paper (systematic review of 
Table 1 Synopsis of all the studies included in the systematic review

\begin{tabular}{|c|c|c|c|c|c|}
\hline Author(s) & Type of study & $\begin{array}{l}\text { No. of cases/ } \\
\text { patients }\end{array}$ & Age (range) & $\operatorname{Sex}(M / F)$ & Results \\
\hline $\begin{array}{l}\text { lacono et al. } \\
(2013)(9)\end{array}$ & $\begin{array}{l}\text { Retrospective } \\
\text { case series }\end{array}$ & $\begin{array}{l}110 \text { knee rx/110 } \\
\text { patients }\end{array}$ & $\begin{array}{l}31 \text { years } \\
(27-38)\end{array}$ & $55 / 55$ & $\begin{array}{l}\text { Linear correlation between femoral width (FW) and } \\
\text { distance of adductor tubercle to joint line (ATJL). The ratio } \\
\text { between FW and ATJL was } 0.543\end{array}$ \\
\hline $\begin{array}{l}\text { lacono et al. } \\
(2014)(10)\end{array}$ & $\begin{array}{l}\text { Prospective } \\
\text { case series }\end{array}$ & $\begin{array}{l}40 \text { knee } r x / 40 \\
\text { patients }\end{array}$ & $\begin{array}{l}73 \text { years } \\
(63-79)\end{array}$ & $23 / 17$ & $\begin{array}{l}\text { ATJL/FW ratio resulted } 0.54 \text { for radiographic measurements } \\
\text { and } 0.53 \text { for intra-operative measurements. No significant } \\
\text { difference between the calculated ratios }\end{array}$ \\
\hline $\begin{array}{l}\text { Luyckx et al. } \\
(2014)(17)\end{array}$ & $\begin{array}{l}\text { Retrospective } \\
\text { case series }\end{array}$ & $\begin{array}{l}100 \text { knee } r x / 100 \\
\text { patients }\end{array}$ & $\begin{array}{l}23 \text { years } \\
20-27)\end{array}$ & $51 / 49$ & $\begin{array}{l}\text { ATJL/FW was found to be } 0.52 \text {. This ratio reconstructed the } \\
\text { joint line within } 4 \mathrm{~mm} \text { of its original level in } 92 \% \text { of the cases }\end{array}$ \\
\hline $\begin{array}{l}\text { Maderbacher } \\
\text { et al. (2014) (18) }\end{array}$ & $\begin{array}{l}\text { Retrospective } \\
\text { case series }\end{array}$ & $\begin{array}{l}80 \mathrm{MRI} \text { knees/80 } \\
\text { patients }\end{array}$ & 29 years & $40 / 0$ & $\begin{array}{l}\text { Strong correlation between FW and ATJL. The best way } \\
\text { to calculate ATJL: } 6.40+[\mathrm{FW}(\mathrm{mm}) \times 0.49]\end{array}$ \\
\hline $\begin{array}{l}\text { Sadaka et al. } \\
(2015)(15)\end{array}$ & $\begin{array}{l}\text { Retrospective } \\
\text { case series }\end{array}$ & $\begin{array}{l}200 \text { knee rx/200 } \\
\text { patients }\end{array}$ & $(20-50)$ & $100 / 100$ & $\begin{array}{l}\text { Significant correlation between FD (femoral diameter) and } \\
\text { ATJL. For female patients ATJL }=0.66 \text { FD }+27.21 \text {, for men } \\
\text { ATJL }=0.82 \text { FD }+25.81\end{array}$ \\
\hline $\begin{array}{l}\text { Gürbüz et al. } \\
(2015)(16)\end{array}$ & $\begin{array}{l}\text { Retrospective } \\
\text { case series }\end{array}$ & $\begin{array}{l}117 \text { knee rx/108 } \\
\text { patients }\end{array}$ & $\begin{array}{l}31 \text { years } \\
(16-82)\end{array}$ & $63 / 45$ & $\begin{array}{l}\text { In Turkish population the ATJL/FW ratio was calculated } \\
0.55 \text {. No significant correlation between the distance } \\
\text { from the fibular head to the JL and FW }\end{array}$ \\
\hline $\begin{array}{l}\text { lacono et al. } \\
(2016)(11)\end{array}$ & $\begin{array}{l}\text { Prospective } \\
\text { case series }\end{array}$ & $\begin{array}{l}21 \mathrm{RTKA} / 21 \\
\text { patients }\end{array}$ & $\begin{array}{l}65 \text { years } \\
(48-83)\end{array}$ & & $\begin{array}{l}\text { Intra-operatively calculated ATJL (using ATJL/FW ratio } \\
0.53 \text { ) was not significantly different than the measured } \\
\text { ATJL obtained after prosthetic component implantation }\end{array}$ \\
\hline $\begin{array}{l}\text { Chen } \\
\text { et al. (2016) (14) }\end{array}$ & $\begin{array}{l}\text { Prospective } \\
\text { case series }\end{array}$ & $\begin{array}{l}16 \text { knee } \\
\text { specimens/120 } \\
\text { TKA }\end{array}$ & $\begin{array}{l}\text { Cadaver } 69 \\
\text { years }(49-88) \\
\text { TKA } 71 \text { years } \\
(46-88)\end{array}$ & $\begin{array}{l}\text { Cadaver } \\
5 / 3 ; \text { TKA } \\
31 / 89\end{array}$ & $\begin{array}{l}\text { It was possible to use the PSAT (posterior slope adductor } \\
\text { tubercle) to precisely locate the adductor tubercle. PDCL } \\
\text { (proximal-distal condylar length)/APCL (anterior-posterior } \\
\text { condylar length) ratio was } 0.77\end{array}$ \\
\hline $\begin{array}{l}\text { Boya et al. } \\
(2017)(20)\end{array}$ & $\begin{array}{l}\text { Retrospective } \\
\text { case series }\end{array}$ & $\begin{array}{l}80 \text { knees } r \times / 80 \\
\text { patients ( } 40 \\
\text { group } 1 \text { and } 40 \\
\text { group 2) }\end{array}$ & $\begin{array}{l}\text { Group } 173 \\
\text { years }(57-91) \\
\text { Group } 233 \\
\text { years }(22-58)\end{array}$ & $\begin{array}{l}\text { Group } 1 \\
\text { 4/36; Group } \\
216 / 24\end{array}$ & $\begin{array}{l}\text { ATJL/FW ratio was significantly greater in group } 2 \\
\text { (without osteoarthritis) in comparison to group } 1 \text { (with } \\
\text { osteoarthritis). Mean ATJL/FW ratio in group } 2 \text { was } 0.522 \text {, } \\
\text { in group } 1 \text { was } 0.502 \text { ) }\end{array}$ \\
\hline $\begin{array}{l}\text { Lee et al. } \\
(2018)(21)\end{array}$ & $\begin{array}{l}\text { Retrospective } \\
\text { case series }\end{array}$ & $\begin{array}{l}60 \text { RTKA/60 } \\
\text { patients }\end{array}$ & 69 years & $22 / 38$ & $\begin{array}{l}\text { Three groups according to prosthesis type: group I ( } 2 \\
\mathrm{~mm} \text { offset), group II ( } 4.5 \mathrm{~mm} \text { offset), group III (2, } 4 \text {, and } 6 \\
\mathrm{~mm} \text { offset). JL position was elevated in all three groups; } \\
\text { in group III was significantly lower than the other two. } \\
\text { However, there was no significant difference in knee } \\
\text { scores (KSKS, KFKS and WOMAC) and ROM among } \\
\text { the three groups. The JL position in revision TKA with } \\
\text { a femoral offset stem was statistically significantly less } \\
\text { elevated than in those with a femoral straight stem }\end{array}$ \\
\hline $\begin{array}{l}\text { Yeh et al. } \\
\text { (2019) (12) }\end{array}$ & $\begin{array}{l}\text { Prospective } \\
\text { case series }\end{array}$ & $\begin{array}{l}78 \mathrm{TKA} / 78 \\
\text { patients }\end{array}$ & $\begin{array}{l}71 \text { years } \\
(46-86)\end{array}$ & $12 / 66$ & $\begin{array}{l}\text { Most metal markers ( } 68 \% \text { ), positioned intra-operative on } \\
\text { adductor tubercle, were located within } 2 \mathrm{~mm} \text { of the inflec- } \\
\text { tion point (formed by the juncture of a proximal concave } \\
\text { curve and a distal convex curve) }\end{array}$ \\
\hline
\end{tabular}


Table 2 Risk of bias assessment for all the trials included in the systematic review

\begin{tabular}{|c|c|c|c|c|c|c|c|}
\hline Study & Sample size & $\begin{array}{l}\text { Power analysis } \\
\text { for sample size }\end{array}$ & $\begin{array}{c}\text { No. of } \\
\text { observers }\end{array}$ & $\begin{array}{l}\text { Independence } \\
\text { of each observer }\end{array}$ & $\begin{array}{c}\text { Professional } \\
\text { profile of the } \\
\text { observer }\end{array}$ & $\begin{array}{l}\text { Intra- and inter- } \\
\text { observer reliability }\end{array}$ & $\begin{array}{c}\text { Repeated } \\
\text { measures in } \\
\text { different times }\end{array}$ \\
\hline Luyckx 2014 (17) & $100 \mathrm{X}$-rays & - & Not reported & Not reported & Not reported & - & - \\
\hline $\begin{array}{l}\text { Maderbacher } \\
2014 \text { (18) }\end{array}$ & $80 \mathrm{MRI}$ & - & 2 & + & Surgeons & + & - \\
\hline $\begin{array}{l}\text { Maderbacher } \\
2015 \text { (19) }\end{array}$ & 200 X-rays & - & 2 & + & Surgeons & + & - \\
\hline Sadaka 2015 (15) & 200 X-rays & - & 3 & + & $\begin{array}{l}1 \text { Surgeon + ra- } \\
\text { diology resident + } \\
1 \text { med student }\end{array}$ & + & - \\
\hline Boya 2017 (20) & $80 \mathrm{X}$-rays & + & 1 & - & Surgeon & $\begin{array}{c}\text { + (only intra- } \\
\text { observer) }\end{array}$ & - \\
\hline Lee 2018 (21) & $75 \mathrm{X}$-rays & - & 2 & + & Surgeons & + & + \\
\hline Iacono 2014 (10) & $\begin{array}{c}40 \text { X-rays + } \\
40 \text { intra-op } \\
\text { measurements }\end{array}$ & + & $\begin{array}{l}3 \text { for } X \text {-ray } 2 \\
\text { for intra-op }\end{array}$ & + & Surgeons for both & + & - \\
\hline Yeh 2019 (12) & $\begin{array}{c}78 \text { X-rays + } \\
78 \text { intra-op } \\
\text { measurements }\end{array}$ & - & $\begin{array}{c}1 \text { for X-ray + } 1 \\
\text { for intra-op }\end{array}$ & + & Surgeons for both & - & - \\
\hline
\end{tabular}

"+" means that the specific aspect considered has been properly addressed by authors (low risk of bias), whereas "-" means that authors did not considered the specific aspect (high risk of bias). Radiographic studies are highlighted in green, intra-op studies in orange, ex-vivo studies in light blue. NA, not applicable.

the literature), no ethical approval was required.

\section{Results}

A total of 13 papers (9-21), published between 2013 and 2019, were included in the present review (Figure 1). Qualitative data synthesis is presented in Table 1.

Among the 13 articles, 9 were retrospective radiographic studies, 3 papers focused on intra-operatively measurements, 1 article was about cadaveric measurements.

\section{Risk of bias assessment}

All the evaluations performed have been collected in Table 2 .
Only three papers $(10,11,20)$ reported the power analysis performed to calculate the sample size of radiographic exams/patients to be included. Anyway, based on the significant results achieved, it is reasonable to assume that all trials included a sufficient sample size.

With regard to the number of observers, in two studies just one observer performed the measurements $(12,20)$, in other two studies $(11,17)$ there is no mention on the number of observers. In ten studies $(9,10,12-16,18,19,21)$ observers were independent from each other. In 7 studies $(9,10,12,16-18,21)$ measurements were performed by orthopaedic surgeons alone, and only in one case there was the involvement of other professional figures. In 5 cases no information about the role of observers were provided 


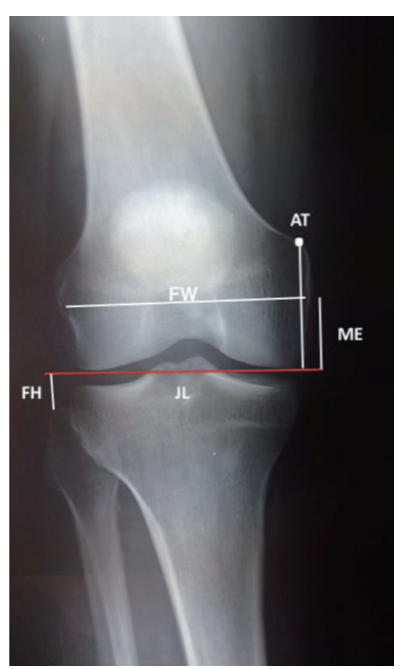

Figure 2 Antero-posterior X-rays summarizing the bony landmarks and the inherent measurements. ME-JL, medial epicondyle-joint line distance; AT-JL, adductor tubercle-joint line distance; FH-JL, fibular head-joint line distance; FW, femoral width at the trans-epicondylar axis. AR, AT-JL distance/FW.

\section{$(11,13,14,16,17)$.}

Intra- and inter-observers reliability data were reported in 11 out of 13 studies (9-11,13-16,18-21).

In only three studies $(13,16,21)$ measurements were repeated by the same observers at different times to further ensure their reliability.

\section{Radiographic studies}

Nine radiographic studies were included.

Iacono et al. in 2013 (9) were the first to propose the use of the "adductor ratio" (AR), i.e., the ratio between the distance of the adductor tubercle from the JL and transepicondylar width of the femur [AR= (AT-JL distance) $/ F W]$. A total of 110 standard antero-posterior radiographs of non-osteoarthritic knees were included, and three different surgeons performed measurements. Three landmarks were considered, i.e., medial epycondile (ME), fibular head (FH) and AT, and for each of them it was calculated the distance to the JL and this distance was correlated to the transepicondylar FW (Figure 2). It was found that both ME-JL and AT-JL distance correlated with FW, but the correlation was statistically stronger when using AT-JL distance $(r=0.83$ vs. $\mathrm{r}=0.52$ for ME-JL).

Luyckx et al. (17) (2014) evaluated 100 antero-posterior knee radiographs. The adductor ratio was the most accurate ratio considered and allowed a very reliable restoration of the joint line (64\% within $2 \mathrm{~mm} ; 92 \%$ within $4 \mathrm{~mm}$ ).

Maderbacher's study group in 2014 (18) evaluated 80 MRI, comparing different methods (including ME-JL distance and FH-JL distance) to accurately individuate joint line: AT was found to be the most reliable landmark to this purpose. They also proposed a new formula to calculate the distance from the AT to the most distal part of medial femoral condyle (MFC), i.e., AT-MFC distance $=6.40+($ femoral width in $\mathrm{mm} \times 0.49)$. The same authors, in a radiographic study on 200 knees, suggested to assess the joint line positioning by measurements performed on the contra-lateral knee: in this case, FH-JL distance was the most reliable parameter, even better than the AT-JL distance (19).

In 2015 Sadaka et al. (15) assessed 200 plan radiographs, recording a significant correlation and linear regression between femoral diameter (FD), and AT-JL distance, defining the adductor tubercle as a valid landmark to accurately position the prosthetic joint within $4 \mathrm{~mm}$ from the native JL height.

Gurbuz et al. (16) in 2015 analyzed 117 plan radiographs to determine JL height, measuring its distance to the adductor tubercle and to the apex of the fibular head; they found out a linear correlation between the femoral width and the AT-JL distance (ratio $=0.55$ ) irrespective of any factors such as age, gender and height in the Turkish population.

Xiao et al. (13) in 2017 investigated the accuracy of 2 different methods for identifying the JL using the adductor tubercle (AT) as the reference landmark [FW and FD to AT-JL distance], in Chinese people. The mean ratio of ATJL/FW was $0.560 \pm 0.03$, and there was no statistical difference between men and women. Using the ratio, the difference between the expected and observed values was limited to $4 \mathrm{~mm}$ in $88 \%$ of cases.

Boya et al. (20) in 2017 analyzed 80 patients, 40 with and 40 without knee OA: the authors raised the problem of JL narrowing, which is a common feature in knees with severe OA: AR was significantly greater in the non-arthritic group in comparison to the arthritic group on plan radiographs. Therefore, they suggest that, in case of advanced OA, surgeons should remove the medial and lateral femoral osteophytes before measuring the FW.

More recently, Yeh et al. (12) in 2019 clarified how to precisely assess the AT position on plan radiographs, defining it as the primary requisite for performing a joint line distance measurement. Their work suggests that the 
radiographic location of AT lays at the inflection point between the concavity of the medial supracondylar ridge (i.e., the medial border of the distal femoral shaft) and the convexity of the proximal aspect of the medial femoral condyle.

\section{Ex vivo studies}

Chen's study group in 2016 (14) described a technique to accurately locate the adductor tubercle. They analyzed 16 cadaveric specimens and 120 knees of patients undergoing TKA, revealing that was possible to use the posterior slopeadductor tubercle (PSAT) juncture, i.e., the corner of the medial and the superior surface of the medial condyle, to locate the adductor tubercle. In 16 cadaveric knees, once the PSAT was engaged, it provided an unambiguous landmark for measuring the distance to the most distal point of the distal femoral condyle. These findings were then confirmed by in vivo evaluations.

\section{Intra-operative studies}

Iacono et al. (10) (2014) applied intra-operatively the (AT-JL distance) /FW ratio in 40 patients. Intra-op. measurements confirmed the role of the AT ratio: (AT-JL distance)/FW ratio, calculated with linear regression, averaged 0.54 for radiographic measurements and 0.53 for intra-operative measurements: no significant differences were found between the (AT-JL distance)/FW ratios on radiographic and intra-operative measurements.

Two years later, Iacono et al. (11) (2016) confirmed the reliability of AT ratio as a helpful landmark, reporting good outcomes in 21 challenging rTKA, and comparing intraoperative measurements with post-operative radiographs. They reported a good ligament balance due to the appropriate JL level achieved by applying the proposed AR. The comparative analysis between the restored JL of the operated knee and the JL of the contralateral native knee revealed no significant difference, in all cases below $5 \mathrm{~mm}$.

Lee et al. (21) (2018) aimed to compare joint line restoration, posterior condyle offset restoration and clinical outcomes in 60 rTKA. They studied 3 groups of patients, treated with 3 different prosthesis with different posterior condyle off-set, finding out that the greater was the offset, the better was the restoration of the joint line. In all cases, the AT ratio was successfully used to restore native JL height.

\section{Discussion}

The main finding of the present review is that AT Ratio is a reliable tool to assess and restore the physiologic joint line level in rTKA, and it shows a satisfactory agreement between radiographic and intra-operative measurements. The review of the available evidence allowed us to elucidate some relevant aspects on the AT both concerning its radiographic evaluation and in vivo application.

AT ratio has gained popularity among surgeons as a valid tool to restore joint line height in rTKA, as showed by the increasing number of studies performed after Iacono et al. (9), who firstly described it in 2013. One of the major findings of the present review is that no highquality comparative study is available and, even if the current evidence suggests the potential of AT ratio, some methodological flaws emerged in any trial included: with regards to sample size, it is reasonable to assume that all the dealt with a sufficient sample size, even though ex-vivo and intraoperative studies analyzed a low number of patients compared to radiographic studies. The number of observers performing the measurements were acceptable in all the papers included, but in most cases just orthopaedic surgeons were involved in radiographic evaluations. A critical issue could lie in the different strategies to locate AT, and some authors tried to describe how to precisely identify it $(12,14)$ : Yeh et al. (12) in 2019 proposed a method to be used on plain radiographs, whereas Chen et al. (14) proposed some practical tricks to be adopted intra-operatively (i.e., the PSAT juncture). In both cases, AT could be easily identified and reliably used for measurement of the JL height.

Anthropometric differences existing among populations may have an impact in the reliability of AT ratio, but the findings of Iacono (9) in an Italian population sample, Gurbuz (16) in Turkish, and Xiao (13) in a Chinese cohort of patients, seem to suggest that the relationship existing between AT-JL distance and FW could be generalized among different populations.

Another matter of concern is the reliability of AT ratio in advanced OA, where JL narrowing and deformation of both femoral condyles and tibial plateau may impair measurements. Boya et al. (20) in 2017 analyzed 80 patients, 40 with and 40 without knee OA: the authors raised the problem of JL narrowing, suggesting that osteophytes could alter AT ratio landmarks, suggesting to avoid osteophytes in radiographs measurements, and to remove them before any intra-op measurements.

Technical difficulties in applying AT ratio in daily 

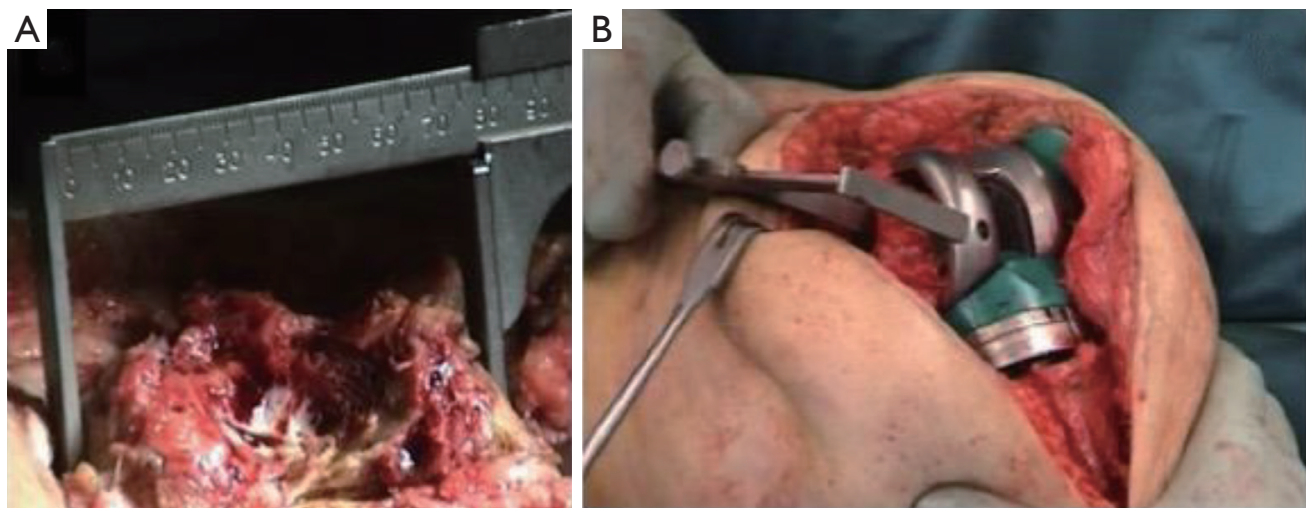

Figure 3 Intra-op application of the AT ratio method as described by Iacono et al.: (A) measurement of the trans-epicondylar FW. The length should be multiplied by 0.53 to calculate the JL distance from the AT; (B) check of the AT-JL distance after prosthesis implantation. The caliper is placed between the AT and the most distal point of the medial condyle of the implant.

clinical practice should be also acknowledged: the caliper positioning might be cumbersome for unexperienced surgeons, and soft tissue presence might bias the acquisition by interposing with the bony structures both at the level of femoral trans-epicondylar measurement and at the AT level (Figure 3). However, in the surgical studies where the intra-tester and inter-tester repeatability of the previous radiographic measurements were verified, a good reliability was reported $(10,11,21)$. Moreover, an intra-operative technique to help surgeon in unambiguously locating the adductor tubercle was described in a cadaveric study (14). Moreover, in complex cases, fluoroscopic control can also be adopted to precisely identify the AT.

The majority of authors agreed that joint line restoration is a crucial step to restore range of movement, to achieve good stability of the implant, and to avoid anterior knee pain syndrome, as largely reported by the current literature $(3,5-8,13,22,23)$ : to this purpose, a difference of maximum $5 \mathrm{~mm}$ or less with respect to the native JL has been found acceptable. This review confirmed the importance of considering a ratio instead of absolute values to determine the JL level both on X-rays and intra-operatively. In fact, JL level determined by measuring the distance of JL from an anatomical landmark such as medial, lateral epicondyle or fibular head $(3,4)$ is of limited usefulness, due to large individual variations in physical sizes $(8,24,25)$. In fact, these distances are likely to change according to the size and morphology of the patient $(8,24,25)$. In addition, when preoperative planning is performed on the pre-operative knee X-rays, the absolute measures might differ from those calculated intra-operatively due to magnification errors.
Conversely, a ratio is not affected by these limitations: if the $\mathrm{FW}$ increases, the distance of AT from JL seems to increase proportionally.

Nowadays, the most used strategies to restore JL height involve the distance from $\mathrm{ME}$ to $\mathrm{JL}$, and the distance from FH to JL, both expressed as a ratio. In particular, the (MEJL distance)/FW seems to be used by most authors (24-26). AT showed superiority versus medial epicondyle distance in 2 of the studies here reviewed $(9,18)$, standing in particular the great variation of medial epicondyle location in knees undergoing revision surgery. Furthermore, the medial epicondyle is more difficult to identify both using $\mathrm{X}$-rays (due to the presence of osteophytes, anatomic variation, knee rotation etc....) and also intra-operatively, due to the coverage of soft tissue. Lastly, the correlation between FW and ME-JL distance, with a coefficient of $0.52(24,25)$, was found to be weaker than the correlation between FW and AT-JL distance, which showed a coefficient of 0.83 with a lower standard deviation (10).

With regards to $\mathrm{FH}$, although the identification of the tip of $\mathrm{FH}$ could be easy on X-rays, during surgery it could be much more challenging. Despite one radiographic study (19) proposed to use $\mathrm{FH}$ in the contralateral knee to calculate $\mathrm{JL}$, reporting very high accuracy, other studies $(16,25)$ did not confirm such reliability versus other methods when applied in replaced knees.

Another relevant aspect is that AT is also a reliable landmark irrespective of any factors such as age, gender, height and ethnicity and, differently from other bony landmarks such as femoral epicondyles, it is not affected by the consequences of bone loss, typical of knee revision 
surgery $(9,16)$. Anyway, as stated above, FW may be wider than normal, due to osteophytes in the medial and lateral epicondyles, while the AT-JL distance may be smaller than normal due to the distal femoral bone loss following component loosening (20). To overcome these problems, femoral width can be measured intraoperatively: if it corresponds to the FW measured on the radiographs, it is possible to use the planned distance from the adductor tubercle to implant the femoral component and restore the $\mathrm{JL}$ position. If not, the intra-operative value of $\mathrm{FW}$ can be used to recalculate the correct JL position, by applying this simple formula: $\mathrm{FW} \times 0.53(9,11)$. Iacono et al. reported a successful JL restoration with equal and symmetric flexion and extension gap in 20/21 RTKAs performed by using this AT ratio method (11): JL restoration was obtained simultaneously to ligament balancing, another challenging and key aspect in revision knee arthroplasty, thus markedly simplifying and shortening surgery.

\section{Conclusions}

Based on the data retrieved from the present review, the adductor tubercle is a reliable and easily detectable landmark, both at X-rays and intra-operatively, and the AT ratio method can help surgeons to restore the JL and achieve ligament balancing, thus simplifying and shortening surgical times in complex revision cases. Anyway, considering some methodological limitations in the available literature, further high quality studies are needed to clarify which methods provides the best reliability in restoring JL in knee revision surgery.

\section{Acknowledgments}

Funding: None.

\section{Footnote}

Reporting Checklist: The authors have completed the PRISMA reporting checklist. Available at http://dx.doi. org/10.21037/atm-20-3681

Conflicts of Interest: All authors have completed the ICMJE uniform disclosure form (available at http://dx.doi. org/10.21037/atm-20-3681). BDM serves as an unpaid editorial board member of Annals of Translational Medicine from $11 / 2018$ to $10 / 2020$. The other authors have no conflicts of interest to declare.
Ethical Statement: The authors are accountable for all aspects of the work in ensuring that questions related to the accuracy or integrity of any part of the work are appropriately investigated and resolved. All the authors have read and approved the final content of the present manuscript, which has been checked to confirm the data contained in it. All the authors declare that the present paper has not been submitted to other journals.

Open Access Statement: This is an Open Access article distributed in accordance with the Creative Commons Attribution-NonCommercial-NoDerivs 4.0 International License (CC BY-NC-ND 4.0), which permits the noncommercial replication and distribution of the article with the strict proviso that no changes or edits are made and the original work is properly cited (including links to both the formal publication through the relevant DOI and the license). See: https://creativecommons.org/licenses/by-nc-nd/4.0/.

\section{References}

1. Schwartz AM, Farley KX, Guild GN, et al. Projections and Epidemiology of Revision Hip and Knee Arthroplasty in the United States to 2030. J Arthroplasty 2020;35:S79-S85.

2. Partington PF, Sawhney J, Rorabeck CH, et al. Joint line restoration after revision total knee arthroplasty. Clin Orthop Relat Res 1999;(367):165-71.

3. Laskin RS. Joint line position restoration during revision total knee replacement. Clin Orthop Relat Res 2002;(404):169-71.

4. Hoeffel DP, Rubash HE. Revision total knee arthroplasty: Current rationale and techniques for femoral component revision. Clin Orthop Relat Res 2000;(380):116-32.

5. Bellemans J. Restoring the joint line in revision TKA: Does it matter? Knee 2004;11:3-5.

6. König C, Sharenkov A, Matziolis G, et al. Joint line elevation in revision TKA leads to increased patellofemoral contact forces. J Orthop Res 2010;28:1-5.

7. Fornalski S, McGarry MH, Bui CNH, et al. Biomechanical effects of joint line elevation in total knee arthroplasty. Clin Biomech (Bristol, Avon) 2012;(8):824-9.

8. Figgie HE, Goldberg VM, Heiple KG, et al. The influence of tibial-patellofemoral location on function of the knee in patients with the posterior stabilized condylar knee prosthesis. J Bone Joint Surg Am 1986;68:1035-40.

9. Iacono F, Lo Presti M, Bruni D, et al. The adductor tubercle: A reliable landmark for analysing the level of the femorotibial joint line. Knee Surg Sports Traumatol 


\section{Page 10 of 10}

Arthrosc 2013;21:2725-9.

10. Iacono F, Raspugli GF, Bruni D, et al. The adductor tubercle as an important landmark to determine the joint line level in total knee arthroplasty: from radiographs to surgical theatre. Knee Surg Sports Traumatol Arthrosc 2014:22:3034-8.

11. Iacono F, Raspugli GF, Filardo G, et al. The adductor tubercle: an important landmark to determine the joint line level in revision total knee arthroplasty. Knee Surgery, Sport Traumatol Arthrosc 2016;24:3212-7.

12. Yeh KT, Chen IH, Wang CC, et al. The adductor tubercle can be a radiographic landmark for joint line position determination: An anatomic-radiographic correlation study. J Orthop Surg Res 2019;14:189.

13. Xiao J, Wang S, Chen $W$ et al. A Study to Assess the Accuracy of Adductor Tubercle as a Reliable Landmark Used to Determine the Joint Line of the Knee in a Chinese Population. J Arthroplasty 2017;32:1351-5.

14. Chen IH, Wu WT, Wang CC, et al. An unambiguous technique for locating the adductor tubercle and using it to identify the joint line. Knee 2016;23:960-3.

15. Sadaka C, Kabalan Z, Hoyek F, et al. Joint line restoration during revision total knee arthroplasty: an accurate and reliable method. Springerplus 2015;4:1-5.

16. Gürbüz H, Çakar M, Adaş M, et al. Measurement of the knee joint line in turkish population. Acta Orthop Traumatol 2015;49:41-4.

17. Luyckx T, Beckers L, Colyn W, et al. The adductor ratio: a new tool for joint line reconstruction in revision TKA. Knee Surgery, Sport Traumatol Arthrosc 2014;22:3028-33.

18. Maderbacher G, Keshmiri A, Schaumburger J, et al. Accuracy of bony landmarks for restoring the natural joint

Cite this article as: Di Matteo B, Altomare D, Dorotei A, Raspugli GF, Bonanzinga T, Marcacci M, Kon E, Iacono F. The reliability of adductor tubercle as an anatomical landmark for joint line restoration in revision knee arthroplasty: a systematic review. Ann Transl Med 2021;9(1):71. doi: 10.21037/atm-203681 line in revision knee surgery: An MRI study. Int Orthop 2014;38:1173-81.

19. Maderbacher G, Keshmiri A, Zeman F, et al. Assessing joint line positions by means of the contralateral knee: a new approach for planning knee revision surgery? Knee Surgery, Sport Traumatol Arthrosc 2015;23:3244-50.

20. Boya $\mathrm{H}$, Araç SŞ. Does severe osteoarthritis in knees with varus deformity alter the adductor ratio? Acta Orthop Traumatol Turc 2017;51:437-41.

21. Lee J, Wang S, Kim K. Is there a difference in joint line restoration in revision Total knee arthroplasty according to prosthesis type? BMC Musculoskelet Disord 2018;19:1-8.

22. Clavé A, Le Henaff G, Roger T, et al. Joint line level in revision total knee replacement: assessment and functional results with an average of seven years follow-up. Int Orthop 2016;40:1655-62.

23. Hofmann AA, Kurtin SM, Lyons S, et al. Clinical and Radiographic Analysis of Accurate Restoration of the Joint Line in Revision Total Knee Arthroplasty. J Arthroplasty 2006;21:1154-62.

24. Griffin FM, Math K, Scuderi GR, et al. Anatomy of the epicondyles of the distal femur: MRI analysis of normal knees. J Arthroplasty 2000;15:354-9.

25. Servien E, Viskontas D, Giuffrè BM, et al. Reliability of bony landmarks for restoration of the joint line in revision knee arthroplasty. Knee Surg Sports Traumatol Arthrosc 2008;16:263-9.

26. Romero J, Seifert B, Reinhardt O, et al. A useful radiologic method for preoperative joint-line determination in revision total knee arthroplasty. Clin Orthop Relat Res 2010;468:1279-83 